\title{
Language and Well-being
}

\author{
Rebecca Fanany \\ Faculty of Arts and Education, Deakin University \\ rebecca.fanany@deakin.edu.au
}

\begin{abstract}
It is generally accepted that there is a close relationship between language and culture and also between culture and the values and perceptions that influence individual actions and behavior. For this reason, study of the relationship between language and well-being has important implications for our understanding of human experience seen through the perspectives of a range of disciplines, including economics, health, education, and culture studies. While well-being is a complex construct that has many aspects and variations, it is also the case that it may be rooted in very basic aspects of human interaction such as language and the ability to communicate. This can be seen as the starting point of a chain of factors that reach into a number of domains of interaction that spread outward from the individual, beginning from a sense of identity and the ability to communicate effectively, and reaching into the macroeconomic environment of education and work.
\end{abstract}

Keywords-well-being, language, happiness, society, human experience

\section{INTRODUCTION}

Well-being has been defined in a number of ways by different authors, depending upon their specific interest. Aristotle, for example, saw eudemonia as the highest human good that represented a process of striving to flourish. There is evidence Aristotle"s view was based on older Greek conceptualizations of happiness (Rowe, 1971). Models of eudemonia were developed in the modern context by Erikson, Maslow, Allport and others. Ryff (1989), for example, suggests there are six aspects of this state: autonomy; personal growth; self-acceptance; purpose in life; environmental mastery; and positive relations with others. Diener (1984) stresses that this type of well-being is a subjective construction or experience that derives from the perceptions of the individual involved. Veenhoven (2000) describes well-being as ,life ability" that allows a person to achieve the goals that will allow him or her to experience positive affect. MacAllister (2005), reviewing the literature on well-being, concluded that this state has both subjective and objective components and involves an absence of illness or pathology that can be observed at both the individual and societal levels. Well-being in this conceptualization involves satisfaction that is wholly separate from economic achievement.

Well-being, which has generally been described in the western context, is of increasing interest in non-western and developing countries. This represents a growing need to understand the dynamic nature of people"s experience within specific sociocultural contexts with their own sets of norms, values, attitudes, and perceptions (Gough et al, 2007; Camfield et al, 2008). Much of the work in the area of international development and the study of poverty has focused on economic measures, but it is becoming more apparent that failure to acknowledge and understand the subjective aspects of people"s experience will result in an incomplete picture of the position of individuals relative to others in the context of their own society and culture (see Rojas, 2007).

Regardless of the exact definition chosen, well-being relates to the subjective affective state experienced by individuals in their interactions with other people in the environment in which they live. These interactions necessarily involve language, at least in a majority of contexts, and occur within a framework of culture associated with the background and origin of the participants. It is generally accepted that there is a close relationship between language and culture (Kramsch, 1998; Risager, 2006; Salzmann et al, 2014) and also between culture and the values and perceptions that influence individual actions and behavior (Diener and Suh, 2000; Markus and Kitayama, 2001; Diener et al, 2003). For this reason, study of the relationship between language and well-being has important implications for our understanding of human experience seen through the perspectives of a range of disciplines, including economics, health, education, and culture studies.

\section{Language and Thought}

\section{METHOD}

The language a person speaks is an integral part of self-perception and contributes to identity as a member of a community and culture. Language provides a framework for thought and perception and also connects the individual to others who speak the same language and share certain common ways of viewing the world. Cognitive processes like these originate in language and are given form by the structures available in the language of question. 
It is generally accepted that any idea can be expressed in any language - this is the basis for translation theory but it is the case that speakers of different languages will conceptualize the same content in different ways. These forms of expression contribute to world view and are not predictable. That is, it is necessary to have knowledge of the way a language is used to understand the contextual boundaries of expression. For example, the term sakit in Indonesian has a range of uses that are both literal and metaphorical. In a literal sense, sakit can mean both ,sick ${ }^{\text {ee }}$ and ,in pain in English. In a metaphorical sense, it can be used in reference to feeling beings, as in sakit hati, in an extension of its literal meaning. However, it can also be used figuratively to refer to non-living items, such as a company or the economy in general, to indicate that something is wrong. In comparison to English, however, the range of use for the term sakit in Indonesian is very broad and covers several different terms and only partially overlaps with English non-literal usage. By contrast, the English word ,happyee covers the meanings of the Indonesia senang, gembira and bahagia. Its range of use, and hence the way in which native speakers conceptualize their experience, encompasses three separate concepts in Indonesian and involves a different set of temporal, affective and cognitive associations.

The idea that the way people think is determined by the language they speak and the corresponding view that speakers of different languages will think and express themselves differently is referred to as linguistic relativity. This principle is often referred to as the Sapir-Whorf Hypothesis, after the linguists who developed it in the $20^{\text {th }}$ century. While the situation is now accepted to be more complex and nuanced than this theory suggests, it is generally agreed that the categories available in a language, as well as its common usage, have the potential to influence thought and also nonlinguistic behavior (see Kay and Kempton, 1984, for discussion of the Sapir-Whorf Hypothesis).

This means that language provides certain, specific ways of looking at the world that are characteristic of the language in question and that are reflected in the words, phrases, and structures the language contains. The nature of any given language is closely related to the culture of the speakers. These two aspects of human society interact, and both have the potential to affect well-being. In this, differences in languages structures may shape perceptions of health and illness, determine the parameters for happiness and other positive affective states, and suggest how individuals should understand their own condition and experience.

\section{Language and Identity}

The language a person speaks is a central aspect of personal identity because it determines membership in a group that consists of all speakers of that language. No matter how different or geographically distant speakers of the same language may be, they nonetheless share certain cognitive features that determine the way in which experience will be perceived and understood. The fact of speaking a particular language automatically links the speaker with others with whom he or she can communicate on a shared basis. This phenomenon is readily observable in Indonesia where virtually every person has a dual identity, as a member of an ethnic group associated with a local language and culture, and as an Indonesian whop is part of a national cultural mainstream that uses Indonesian. The usual sociolinguistic practice where individuals switch into their local language when conversing with others from the same ethnic groups demonstrates the group identity that is associated with language use and that is a central feature of personal identity (see Effendi and Fanany, 1999).

For this reason, loss of a person's native language is a very serious challenge to well-being that can have serious psychological consequences. For people who are separated from the community that uses their language, the need to speak and interact in a different language can be very stressful, even if ability in the second language is good. In many cases, however, it is difficult for people to master a second language to a high level. These people may experience some degree of linguistic isolation. Linguistic isolation refers to the situation where an individual does not have the opportunity to interact in his or her native language and also has difficulty using the majority language in all relevant social contexts. This situation is often most pronounced among vulnerable populations such as migrants (especially those with low levels of education), refugees, the elderly, and people from small language communities (Ward and Styles, 2003; Kerswill, 2006).

Linguistic isolation is often contextual. That is, people may be able to use their native language in certain settings (such as in the home) but be unable to use the majority language to the degree required to interact effectively in the public sphere. Other speakers may be able to use the majority language relatively well but have no contact with other speakers of their first language. Still others may have the opportunity to use their first language but have low or limited fluency in the majority language. Any of these situations can have a serious impact on the emotional state of the people involved and may detract significantly from their well-being as well as their mental and physical health (Extra and Verhoeven, 1999).

Personal linguistic identity is central to peoplecs association with an ethnic group based on heredity and traditional ties. In this, language is part of the cultural background people inherit from parents and grandparents that links them to the customs and traditions of their ancestors. For this reason, the question of linguistic identity is often central to demands for political recognition by members of ethnic groups whose language and culture differ from the mainstream in their nation or 
region. In Europe in the $18^{\text {th }}$ and $19^{\text {th }}$ century, for example, rising nationalist movements were often aligned with majority language use, and the modern European nations remain very much defined by the language of their traditional residents (French is spoken in France; German is spoken in Germany; etc) (see Barbour and Carmichael, 2000).

Another important element of language use and identity relates to the social markers discernable in the speech of different individuals and groups. It has long been observed that people from different social groups speak and use language in different ways. Most people are quite sensitive to the social cues indicated by language use in their native language and subconsciously use this information to categorize others. They also adjust their own language use to fit better into the social context. As this suggests, native speakers have the ability to use and understand a number of different codes and registers in their first language. A code is a form of language use where specific meanings are embedded in the social context. Native speakers can switch codes instantly depending on the social context (Crystal, 1997). A register is a style or genre of language that is deemed appropriate by native speakers for use in a particular linguistic context (Crystal, 1997). In practice, it is extremely difficult for non-native speakers, no matter how skilled, to master the social aspects of language use to a level comparable to a native speaker.

This ability to switch codes and make use of different registers allows native speakers flexibility in communication and provides a great deal of information about other people and the social context (Coulmas, 2005). People who are deprived of this potential because they do not speak the majority language or do not speak it well enough to understand the social nuances will not only be socially isolated but may experience significant psychosocial effects because of their inability to communicate fully. The result may be depression and anxiety but also frustration, embarrassment, and inability to form meaningful relationships as well as boredom and isolation from the mainstream culture (Miller and Rasco, 2004). A great deal of our social experience is mediated by language, and an understanding of the language used in a person"s environment provides a wealth of information about other people and the intangible social context of society. The impact of this situation on well-being may be severe because of the centrality of the need to communicate fully and in all social contexts as well as the universal need of human being for fulfilling social interaction.

\section{Language and Health}

The enjoyment of good health is a central aspect of well-being, as well as of the associated concept of quality of life. As noted above, the absence of disease or pathology is integral to the experience of well-being. For this reason, the role of language in the context of health and health care is an important determinant of outcomes and also of well-being in the larger sense. Language is multifaceted and involves thinking, comprehension, aural ability (the ability to hear and differentiate sounds), imitative ability, logic, time sense, and many other aspects of the interpretation of individual and collective experience. The experience of health and illness as well as well-being is expressed through language, and health professionals rely on being able to obtain meaningful information about this experience from patients or clients that will help them provide the most effective treatment. Communication breakdown often occurs, however, when the cognitive framework of clients and patients is different from that of the health professional.

A person"s first language will determine what is considered a symptom of illness, what kinds of symptoms require treatment or professional advice, how that advice will be interpreted, and whether and to what extent it will be implemented (Bischoff et al, 2003). These aspects of cognition in a person"s first language may or may not correspond to the conceptualizations of health professionals. Similarly, language ability determines how a person will explain his or her personal health and how and to what extent he or she will understand health advice (Wilson et al, 2005). It is not just verbal features of language that are important in this context, but also non-verbal mannerisms, such as facial expression, manner, tone of voice, and so forth (Schouten and Meeuwesen, 2006).

Communication breakdown often occurs in the health care context. This can take place when the health professional uses a different code or register from patients or clients. That is, the health care professional may use words and expressions to talk about health that are not known or understood by members of the general public (even if they speak the same language). Health professionals have a tendency to talk about their field in a jargon that was part of their professional training and that marks them as members of a profession (Stevenson et al, 2004). Communication breakdown can occur when meaning is constructed differently by health professionals and their clients or patients. This is a case of cognitive framework being different and individuals categorizing health information in different ways.

For example, communication between health professionals and patients or clients can fail if the first language of the person seeking treatment does not encompass their problem. This means that the individual cannot conceptualize what is meant by the health professional. This may occur when a patient or client speaks a language that does not have a tradition of diagnosis or internal medicine and/or is very different in structure than the language of interaction. This issue is particularly relevant in Indonesia, which does not have an indigenous traditional of internal medicine, and terms used to discuss disease in the modern content are often borrowed from English. For example, as the population ages, chronic conditions are 
becoming more prevalent in Indonesia. Among these is cancer, which is an increasing concern among the older population in Indonesia as it is elsewhere in the world. However, Indonesian, and also the various local languages in use by the population, lacks a traditional terms for this disease because it does not have characteristic symptoms that distinguish it from other conditions. The loan word kanker must be used, which does not correspond to a specific traditional concept of illness and hence does not fit into the cognitive framework of speakers. This is not to say that the modern concept of cancer is not understood by Indonesian speakers; it may well be but draws its characteristic features from the modern context which entered peoplees understanding fairly recently. As a result, understanding of this concept tends to be associated with higher levels of Indonesian mastery (ie with higher levels of formal education) but it nonetheless lacks traditional affective connotations. These aspects of interpretation have also tended to come from outside Indonesia along with content aspects of meaning.

Not surprisingly, language ability has the potential to affect interactions between health professionals and their patients or clients. Before people even seek health advice, however, difficulties interacting with the wider community because of language problems have the potential to seriously affect their health. As noted, the psychosocial effects of linguistic isolation include loneliness, depression, and inability to form meaningful relationships, boredom, anxiety, frustration, embarrassment, alienation, and disconnection. These effects have been shown to relate directly to many health issues. For example, research has shown that immigrants to many countries report high levels of drug use that decline with acculturation (Grusser et al, 2005; Reimer et al, 2007; Prado et al, 2008); that foreign born children in the US tend to be healthier than children of the same age born in the US in linguistically isolated households (Lucas et al, 2005); that $40 \%$ of elderly Asians in new York City have clinical symptoms of depression (Rhee, 2009); that Asian women in the US aged over 65 years have a suicide rate more than double that of English-speaking women of the same age (Treas and Mazumdar, 2002); that the hepatitis B virus infection rate among linguistically isolated Asians in the US is $15-20 \%$ but only $0.4 \%$ for the population as a whole (Levy et al, 2005); that linguistically isolated women experience domestic violence at a rate of about $30-50 \%$ compared to about $16 \%$ for women in general (Pan et al, 2006); that children whose parents are linguistically isolated have high rates of developmental, academic, behavioral, and social problems that often persist into adulthood and may be passed from generation to generation (Yu et al, 2009); among many other similar effects. In Australia, high levels of acculturation stress among Sudanese migrants due to linguistic isolation have been observed (Milner and Khawaja, 2010). Older male migrants from Italy experience depression at twice the rate of the non-migrant population of the same gender and age (Stanaway et al, 2010); and Arabic speaking, Muslim migrants, especially female migrants, to Australia suffer from depressive and anxiety conditions proportional to their linguistic isolation and separation from their culture (Khawaja, 2007). All of these observations have been associated with inability to use the majority language to the degree required to participate in ordinary social interactions. It must be recalled, however, that while there may be a number of commonalities in the experiences of different groups in different locations, the specific characteristics of the society and culture of the group of interest as well as those of the society and culture they are living in must be considered. Also, the nature of nonmajority language communities in different locations varies greatly and depends on geographical location, migration policies, population levels, and a whole range of political and social issues.

\section{Language and Employment}

In assessing the impact that limited language proficiency may have on well-being, the relationship between language and economic participation must be considered. The ability to work and make a living is representative of a person or group"s integration into society and can be readily measured, and financial stability has been shown to contribute to wellbeing (Di Tella et al, 2003). While it is difficult to assess potential health effects for a given population (because assessment is necessarily based on probabilities of risk), there is a strong relationship between income, and hence socioeconomic status as a whole, and health. Higher SES tends to be associated with better health and lower SES with worse health (Berkman et al, 2014). Health, in turn, is integral to well-being, suggesting that well-being cannot be fully understood without insight into the role of SES as a determinant of cognitive state.

It has been observed that migrants often earn less than native born workers, and this phenomenon is often explained in terms of human capital (see Chiswick and Miller, 2008, 2009). Human capital is the sum of all the attitudes, capabilities, knowledge, and skills people have that allow them to work and produce economic value. Language is an important aspect of human capital and one which is often overlooked in attempting to understand the differential impacts of employment outcomes. Traditionally, assimilation of non-native speakers has been measured by how quickly they acquire the ability to function in an economy which relies on a language they do not speak, and an important measure of this has been the acquisition of the majority language. Research has shown that language ability, fluency in spoken language as well as literacy in written language, is significant for labor market success around the world (see, for example, Rivera-Batiz, 1990; Chiswick, 1991; Dustmann, 1994; Chiswick and Miller, 1995; Chiswick et al, 1997), suggesting that this 
phenomenon applies across cultures. In Australia, for example, migrants from a non-English speaking background (NESB) have greater difficulty obtaining work and an income level commensurate with their qualifications than do Australian-born workers or migrants from English-speaking countries (Colic-Peisker, 2011). In the US, a disproportionate number of linguistically isolated households (where the wage earners in the home lack fluency in the majority language) are among the poorest in the nation (US Census Bureau, 2000). In countries like Australia, institutionally set wages provide some protection for those who do not speak English well. This means that non-English speaking migrants to Australia tend to do relatively well in terms of income in low skilled job requiring little language ability. However, the wage protection that is an advantage in the jobs at the bottom of the earnings scale restricts the earning potential of this same group and constrains upward mobility (Chiswick et al, 2008).

The impact of this is particularly significant for the well-being of children because it is their parents or guardians who make decisions about their health and health care. A great deal of research has found that poverty, as a measure of SES, is an important determinant of children"s health (see, for example, St Peter et al, 1992; Newacheck et al, 1996; Brooks-Gunn and Duncan, 1997). Language ability contributes to this, as many people living below the poverty line tend to lack proficiency in the majority language. Parents who do not speak the majority language may be unable to find health professionals with whom they can communicate effectively and who understand their knowledge and beliefs about health. In the US, for example, the health status of Hispanic children has been found to be significantly lower than that of white children, and it has been shown that this disadvantage can be explained by language ability of parents and factors associated with not being a speaker of English as well as different, culturally and linguistically determined beliefs and views about health care and the health care system (Weinick and Krauss, 2000). In Australia, which has always experienced high levels of immigration, little research has been done on this group, but available studies suggest that immigrant children experience a number of disadvantages, including lower education outcomes, racism, separation from cultural and social networks, identity issues, and lack of access to health and social services. Nonetheless, it has also been suggested that the well-being of immigrant children in Australia is still higher than that of migrants to other OECD countries (Katz and Redmond, 2010).

Educational attainment is very closely related to employment; jobs with better pay generally require higher levels of education. The ability to succeed in formal education is dependent on language ability, and language status can be a major factor in success in both education and employment (Chiswick and Miller, 2009). For people who cannot gain a reasonable level of fluency in the majority language, the only option for employment may be unskilled or low skilled jobs that do not require much direct interaction with others through language. Jobs of this kind may be inadequate to support the needs of the individual and his or her family and may also be emotionally unsatisfactory. It has been shown that language ability is an important predictor of higher employment status and lower incidence of psychosocial problems (Beiser and Hou, 2001).

Language, then, is an aspect of human capital and relates to the ability to adapt to a new social environment. Children often adapt to cultural change more readily than adults, largely because younger people tend to be more able to learn a new language than older people. By contrast, adults may have more difficulty learning a new language and may suffer more from a loss of social status in a non-native culture (Munoz, 2006). The ability to play a socially meaningful role in a person"s culture of origin often cannot be duplicated in a new society because of the fundamental role language plays in social interaction (see, for example, Miller, 1999; Miller et al, 2002; Colic-Peisker and Walker, 2003). In fact, role reversal often occurs in the new environment, as children become fluent in the majority language faster and have to take on some of the responsibilities of their parents who have difficulty interacting in the public sphere. This situation is particularly significant in Indonesia which has long experienced high levels of domestic migration, which has tended to involve individuals from rural areas who move to urban centers to improve their economic position.

\section{FINDING AND DISCUSSION}

In Indonesia, location of birth is associated with first language, as use of the nation es approximately 700 local languages relates to geographic origin. Similarly, employment in the formal sector relies on ability to use Indonesian at near native level. The problem of people who cannot master Indonesian has not received a level of attention commensurate with its implications (see Fanany, 2013a, 2013b for discussion of this) but is part of the network of determinants that contribute to well-being in the Indonesian population. It is generally assumed that children will master Indonesian in school, which uses the national language as the language of instruction and also teaches Indonesian as a subject area. This formal training is supported by use of the language in the public environment, including the media, which tends to be very significant for children in the form of television (see Kitley, 2014). However, little attention has typically been paid to those individuals who do not master the language to a high level, despite this exposure; to the language mastery of individuals who leave school before reaching the age at which it is legally sanctioned to leave school; to the reasons for lack of success in formal 
education experienced by some individuals; to differential achievement rates across regions; or to the complexity of factors that lead to students dropping out of school (see Fanany, 2012b).

One factor that has contributed to inability in Indonesian being overlooked in considerations of well-being is that Indonesia has a large informal sector that has traditionally absorbed individuals who are only capable of interacting fluently in their first language, which is typically a local language but increasingly may be a highly informal, non-standard dialect of urban Indonesian (see Fanany, 2013a). Inability to use Indonesian may also mean that the individual is geographically restricted to locations where his or her local language is used. Overall, being limited to employment in the informal sector means opportunities may be reduced and earning potential impacted. Perhaps more important, individuals who do not speak Indonesian well cannot participate in the dynamic national culture that uses the national language. In current society, official interaction with government, education, health care, and the media all require high level use of Indonesian. The new media is extremely popular in Indonesia as well and tends to use Indonesian, albeit informal, highly colloquial codes are often observed. A person who cannot speak Indonesian, then, may experience social exclusion across a number of spheres, a condition that has been shown to contribute to a lack of well-being and serious psychosocial impacts (Baumeister et al, 2002; MacDonald and Learey, 2005). This type of social inclusion has also been found to have intergenerational impacts and to have significant economic impacts for a whole society (Scott et al, 2001; Bynner and Parsons, 2002).

The effects of social exclusion and restrictions on individual initiative that emerge from language status are significant for well-being, which, as discussed above, is a cognitive and affective state that reflects the individual's perceptions of his or her own experience. While well-being is a complex construct that has many aspects and variations, it is also the case that it may be rooted in very basic aspects of human interaction such as language and the ability to communicate. This can be seen as the starting point of a chain of factors that reach into a number of domains of interaction that spread outward from the individual, beginning from a sense of identity and the ability to communicate effectively, and reaching into the macroeconomic environment of education and work. This is particularly significant in Indonesia in light of the nation"s extremely complex linguistic and cultural context.

\section{CONCLUSION}

It is worth noting that the era of regional autonomy which began in 2001 has seen an increased interest in local language interaction in the public sphere that stands in contrast to language policies in earlier historical periods. The phenomenons of regional regulations that relate to the use of local language (perda bahasa) in the public sphere are evidence of this. While a number of factors have contributed to the passing of such laws and include a desire to promote tradition use of heritage language and the perception of language pressure from both Indonesian and English (see Spolsky, 2004), it may also be that these local laws have been supported by politicians and the public because of an awareness of the impact of communication problems on the well-being in local communities, even if the issue has not been formally conceptualized in this manner. This can be taken as evidence of the importance of considering language when assessing well-being and also as one means of understanding the experience of people in the modern society of Indonesia and the potential impacts social change and globalization may have on their perceptions and satisfaction with their life.

\section{References}

Aristotle. (1980) The Nicomachean Ethics. (Ross, D and Brown, L, eds). Oxford University Press, Oxford, UK.

Barbour, S \& Carmichael, C. (2000) Language and Nationalism in Europe. Oxford University Press, Oxford, UK.

Baumeister, RF, Twenge, JM \& Nuss, CK (2002) "Effects of Social Exclusion on Cognitive Processes: Anticipated Aloneness Reduces Intelligent Thought," Journal of Personality and Social Psychology, 83(4). 817.

Beiser, M and Hou, F (2001) "Language Acquisition, Unemployment and Depressive Disorder among Southeast Asian Refugees: A 10-year Study," Social Science and Medicine, 53. 1321-1334.

Berkman, LF, Kawachi, I and Glymour, M, eds (2014) Social Epidemiology, Oxford University Press, Oxford, UK and New York.

Bischoff, A, Bovier, PA, Isah, R, Francoise, G, Ariel, E and Louis, L (2003) "Language Barriers between Nurses and Asylum Seekers: Their Impact on Symptom Reporting and Referral," Social Science \& Medicine, 57(3): 503-512.

Brooks-Gunn, J and Duncan, GJ (1997) "The Effects of Poverty on Children," Future Child, 7: 55-71.

Bynner, J and Parsons, S (2002) "Social Exclusion and the Transition from School to Work: The Case of Young People Not in Education, Employment, or Training (NEET)," Journal of Vocational Behavior, 60(2): 289-309.

Chiswick, BR (1991): "Speaking, Reading, and Earnings among Low-Skilled Immigrants", Journal of Labor Economics, 9: 149-170.

Chiswick, BR and Miller, PW (1995): "The Endogeneity between Language and Earnings: International Analyses," Journal of Labor Economics, 13: 246-288. 
Chiswick, BR and Miller, PW (2008) "Why is the Pay Off to Schooling in Smaller for Immigrants?" Labor Economics, 15 (6): 1317-1340.

Chiswick, BR and Miller, PW (2009) “The International Transferability of Immigrants Human Capital," Economics of Education Review, 28 (2): 162-169.

Chiswick, BR, Cohen, Y, Zach, T (1997): "The Labor Market Status of Immigrants: Effects of the Unemployment Rate at Arrival and Duration of Residence", Industrial and Labor Relations Review, 50(2): 289-303.

Chiswick, BR, Le, AT and Miller, PW (2008) "How Immigrants Fare Across the Earnings Distribution in Australia in the United States," Industrial and Labor Relations Review, 61 (3): 353-373.

Colic-Peisker, V (2011) "Ethnicse and „Anglos"e in the Workforce: Advancing Australia Fair?” Journal of Intercultural Studies, 32 (6): 637-654.

Colic-Peisker, V and Walker, I (2003) "Human Capital, Acculturation and Social Identity: Bosnian Refugees in Australia," Journal of Community and Applied Social Psychology, 13: 337-360.

Coulmas, F (2005) Sociolinguistics: The Study of Speakers' Choices, Cambridge University Press, Cambridge, UK.

Crystal, D (1997) The Cambridge Encyclopedia of Language, Cambridge University Press, Cambridge.

Diener, E (1984) "Subjective Well-Being," Psychological Bulletin, 95: 542-575.

Diener, E and Suh, EM (2000) Culture and Subjective Well-Being, MIT Press, Boston, MA.

Diener, E, Oishi, S and Lucas, RE (2003) "Personality, Culture, and Subjective Well-Being: Emotional and Cognitive Evaluations of Life," Annual Review of Psychology, 54 (1): 403-425.

Di Tella, R, MacCulloch, RJ and Oswald, AJ (2003) "The Macroeconomics of Happiness," Review of Economics and Statistics, 85(4): 809-827.

Dustmann, C. (1994): "Speaking Fluency, Writing Fluency and Earnings of Migrants," Journal of Population Economics, 7: 133-156.

Fanany, R and Effendi, ZM (1999) "Minangkabau Children to Indonesian Adults: Promoting Public Policy through Indonesian Language Teaching in West Sumatra, Indonesia," Crossroads: An Interdisciplinary Journal of Southeast Asian Studies, 13 (1): 105-113.

Extra, G and Verhoeven, L, eds (1998) Bilingualism and Migration, Mouton de Gruyter, Berlin.

Fanany, R (2013) "Language and Culture as Social Determinants of Health in the Context of Urbanization," in Urban Mobility: Textual and Spatial Urban Dynamics in Health, Culture and Society : Proceedings of the Third International Conference on Urban Mobility: Its Impacts on Socio-cultural and Health Issues 2012, Universitas Airlangga, Surabaya, Indonesia, pp. 88-95.

Fanany, R (2013) "Training Teachers for Multilingual and Multiethnic Classrooms in Indonesia," in ITEC 2013 : Building Milestones for Global Partnerships and Development in Education : Proceedings of the International Teacher Education Conference, University of Lampung, Bandar Lampung, Indonesia, pp. i-ix.

Gough, I, McGregor, JA and Camfield, L (2007) “Theorising Well-being in International Development," in Gough, I and McGregor, JA, eds, Well-being in Developing Countries: New Approaches and Research Strategies, Cambridge University Press, Cambridge, UK, 3-44.

Grüsser, SM, Wölfling, K, Mörsen, CP, Albrecht, U, and Heinz, A (2005) "Immigration-Associated Variables and Substance Dependence," Journal of Studies on Alcohol and Drugs, 66 (1): 98-104.

Katz,I and Redmond, G (2010) "Review of the Circumstances among Children in Immigrant Families in Australia," Child Indicators Research, 3 (4): 439-458.

Kay, P and Kempton, W (1984) "What Is the Sapir-Whorf Hypothesis?" American Anthropologist, 86 (1): $65-79$.

Kerswill, P (2006) "Migration and language," in Mattheier, K, Ammon, U, and Trudgill, P, eds, Sociolinguistics/Soziolinguistik: An International Handbook of the Science of Language and Society," De Gruyter, Berlin, 1-27.

Khawaja, NG (2007) "An Investigation of Psychological Distress of Muslim Migrants in Australia," Journal of Muslim Mental Health, 2: 39-56

Kitley, P (2014) Television, Nation, and Culture in Indonesia, Ohio University Press, Athens, $\mathrm{OH}$.

Kramsch, C (1998) Language and Culture, Oxford University Press, Oxford, UK.

MacDonald, G and Leary, MR (2005) "Why Does Social Exclusion Hurt? The Relationship between Social and Physical Pain," Psychological Bulletin, 131(2): 202.

Markus, HR and Kitayama, S (2001) “The Cultural Construction of Self and Emotion: Implications for Social Behavior," in Parrott, WG, ed, Emotions in Social Psychology, Psychology Press, New York and Howe, UK, 119-137.

McAllister, F. (2005). Well-being Concepts and Challenges, SDRN Discussion Paper, DEFRA, www.apho.org.uk/resource/view.aspx?RID 
Miller, KE (1999) "Rethinking a Familiar Model: Psychotherapy and the Mental Health of Refugees," Journal of Contemporary Psychotherapy, 29: 283-304.

Miller, KE and Rasco, LM (2004) The Mental Health of Refugees: Ecological Approaches to Healing and Adaptation, Lawrence Erlbaum Associates, Mahwah, NJ.

Miller, KE, Weine, SM, Ramic, A, Brkic, N, Bjedic, ZD, Smajkic, A et al (2002) “The Relative Contribution of War Experiences and Exile-Related Stressors to Levels of Psychological Distress Among Bosnian Refugees," Journal of Traumatic Stress, 15: 377-387.

Milner, K and Khawaja, NG (2010) "Sudanese Refugees in Australia: The Impact of Acculturation Stress," Journal of Pacific Rim Psychology, 4 (1): 19-29.

Munoz, C, ed (2006) Age and the Rate of Foreign Language Learning, Multilingual Matters, Clevedon, UK.

Newacheck, PW, Hughes, DC, and Stoddard, JJ (1996) "Children's Access to Primary Care: Differences by Race, Income, and Insurance Status," Pediatrics, 97:26-32.

Pan, A, Daley, S, Rivera, LM, Williams, K, Lingle, D and Reznik, V(2006) "Understanding the Role of Culture in Domestic Violence: The Ahimsa Project for Safe Families” Journal of Immigrant and Minority Health, 8 (1): $35-43$.

Prado, G, Szapocznik, J, Maldonado-Molina, MM, Schwartz, SJ, and Pantin, H (2008) "Drug Use/Abuse Prevalence, Etiology, Prevention, and Treatment in Hispanic Adolescents: A Cultural Perspective," Journal of Drug Issues, 38(1): 5-36.

Reimer, J, Lorenzen, J, Baetz, B, Fischer, B, Rehm, J, Backmund, M, and Haasen, C (2007) “Injection Drug Use, Multiple Hepatitis Virus Infections, and Migration: A German Study," Substance Use and Misuse, 42 (9): 1353-1365.

Risager, K (2006) Language and Culture: Global Flows and Local Complexity, Multilingual Matters, Clevedon, UK, Buffalo and Toronto.

Rivera-Batiz, FL (1990): "English Language Proficiency and the Economic Progress of Immigrants", Economics Letters, 34: $295-300$.

Rojas, M (2007) "The Complexity of Well-being: A Life-Satisfaction Conception and a Domains-of-Life Approach," in Gough, I and McGregor, JA, eds, Well-being in Developing Countries: New Approaches and Research Strategies, Cambridge University Press, Cambridge, 259-280.

Rowe, CJ (1971) The Eudemian and Nicomachean Ethics: A Study in the Development of Aristotle's Thought, Cambridge Philological Society, Cambridge, UK.

Ryff, CD (1989) "Happiness is Everything, or Is It? Explorations on the Meaning of Psychological Well-Being," Journal of Personality and Social Psychology, 57: 1069-1081.

Salzmann, Z, Stanlaw, J and Adachi, N (2014) Language, Culture, and Society: An Introduction to Linguistic Anthropology, Westview Press, Boulder, CO.

Scott, S, Knapp, M, Henderson, J and Maughan, B. (2001) "Financial Cost of Social Exclusion: Follow Up Study of Antisocial Children into Adulthood," BMJ, 323(7306): 191.

Schouten, BC and Meeuwesen, L (2006) "Cultural Differences in Medical Communication: A Review of the Literature," Patient Education and Counseling, 64(1): 21-34.

Spolsky, B (2004) Language Policy, Cambridge University Press, Cambridge, UK.

St Peter ,RF, Newacheck, PW, and Halfon, N (1992) “Access to Care for Poor Children: Separate and Unequal?" JAMA, 267:2760-2764.

Stanaway, F et al., (2010) "Depressive Symptoms in Older Male Italian Immigrants in Australia: The Concord Health and Aging in Men Project," Medical Journal of Australia, 192 (3): 158-162.

Stevenson, FA, Cox, K, Britten, N and Dundar, Y (2004) "A Systematic Review of the Research on Communication between Patients and Health Care Professionals about Medicines: The Consequences for Concordance," Health Expectations, 7(3): 235-245.

Treas, J and Mazumdar, S (2002) "Older People in America's Immigrant Families: Dilemmas of Dependence, Integration, and Isolation" Journal of Aging Studies, 16 (3): 243-258.

Veenhoven, R (2000) "The Four Qualities of Life: Ordering Concepts and Measures of the Good Life," Journal of Happiness Studies, 1: 1-39.

Ward, C and Styles, I. (2003) "Lost and Found: Reinvention of the Self Following Migration," Journal of Applied Psychoanalytic Studies, 5 (3): 349-367.

Weinick, RM and Krauss, NA. (2000) "Racial/Ethnic Differences in Children's Access to Care," American Journal of Public Health, 90 (11): 1771-1774.

Wilson, E, Chen, AH, Grumbach, K, Wang, F, and Fernandez, A. (2005) "Effects of Limited English Proficiency and Physician Language on Health Care Comprehension," Journal of General Internal Medicine, 20(9): 800-806. 